\title{
Quality of life questionnaire for women with gestational diabetes mellitus (GDMQ- 36): development and psychometric properties
}

\author{
S. Mokhlesi ${ }^{1}$, M. Simbar $^{2 *}$, F. Ramezani Tehrani ${ }^{3}$, N. Kariman ${ }^{4}$ and H. Alavi Majd ${ }^{5}$
}

\begin{abstract}
Background: Gestational diabetes mellitus carries serious risks to mother and fetus and causes social, mental, and psychological consequences which can affect mothers' quality of life. Accordingly, this study aims to develop and assess the psychometric properties of quality of life questionnaire for women with gestational diabetes mellitus.

Methods: A methodological study of sequential exploratory mixed method was developed and implemented. It included qualitative (development of a quality of life questionnaire for mothers with GDM) and quantitative (assessment of psychometric prosperities of quality of life questionnaire for mothers with GDM) phases.

Results: Based on the findings of the qualitative phase and literature review, the primary questionnaire was prepared with 142 items. The outcome of face validity and content validity assessment was a 67-item questionnaire. S-CVI and S-CVR turned out to be 0.92 and 0.68 , respectively. The results of exploratory factor analysis yielded an instrument with 36 items in five domains including concerns about high-risk pregnancy, perceived constraints, disease complications, medication and treatment, and support. Five factors explained $46.68 \%$ of the total variance of the questionnaire. The results indicated a moderate and significant correlation between the questionnaire of "Diabetes Clients Quality Of Life" and the researcher-made questionnaire $(r=0.63)$. Cronbach's alpha coefficient for the entire scale was 0.93 and the intra-class correlation coefficient was 0.95 .
\end{abstract}

Conclusion: Quality of life questionnaire for mothers with GDM is a valid and reliable tool capable of measuring the quality of life of women with GDM.

Keywords: Quality of life, Gestational diabetes mellitus, Questionnaire development, Psychometric properties of questionnaire

\section{Background}

Diabetes is the most common and prevalent medical condition in pregnancy, which is defined as varying degrees of carbohydrate intolerance diagnosed or initiated during the pregnancy for the first time. This definition is applied regardless of insulin administration for treatment [1]. The prevalence of gestational diabetes is increasing worldwide including Iran; in one meta-analysis,

\footnotetext{
* Correspondence: msimbar@yahoo.com

${ }^{2}$ Professor, Midwifery and Reproductive Health Research Center, Shahid

Beheshti University of Medical Sciences, Tehran, Iran

Full list of author information is available at the end of the article
}

the prevalence of Gestational Diabetes in Iran was estimated as $4.9 \%$ [2].

GDM is associated with many psychological and social consequences in addition to increased risks for mother and fetus $[2,3]$. Studies have shown that after a positive screening, anxiety and worry increased in these women about the likelihood of chronic diabetes and their babies' health (the effect of insulin or diet on the fetus), thus reducing their perception of health. Further, for some women, GDM carries a stigma and they are ashamed to express it [4-6]. A study in China indicated that approximately 260,000 QALYs (quality adjusted life years) were lost over a 3-month period due to maternal

(c) The Author(s). 2019 Open Access This article is distributed under the terms of the Creative Commons Attribution 4.0 International License (http://creativecommons.org/licenses/by/4.0/), which permits unrestricted use, distribution, and reproduction in any medium, provided you give appropriate credit to the original author(s) and the source, provide a link to the Creative Commons license, and indicate if changes were made. The Creative Commons Public Domain Dedication waiver (http://creativecommons.org/publicdomain/zero/1.0/) applies to the data made available in this article, unless otherwise stated. 
complications associated with GDM during pregnancy and childbirth [7]. All of these consequences can affect the quality of life of mothers with GDM.

Health-related quality of life represents a measure of physical and social activity as well as mental health and is considered as an important health indicator [8]. Today, the evaluation and record of health-centered quality of life via quality of life questionnaires have become crucial in medical and nursing interventions [9]. The quality of life of mothers with GDM has also been evaluated in related studies. In the study by Kepk et al., for mothers with GDM, SF-8 quality of life questionnaire was completed on weeks 27 and 36, where GDM had no significant effect on their physical, mental, occupational, or schooling dimensions [10]. Tratnowski et al. used WHOQOL-Bref questionnaire to assess the quality of life of mothers with GDM. The mean score of physical, mental, and social aspects in this questionnaire decreased significantly from mid to late pregnancy [11]. In the study by Dalfera et al., evaluating the quality of life of pregnant mothers with diabetes, the scores for mental aspect obtained from SF-36 questionnaire were not significantly different between mothers with GDM and the control, though the mothers' physical aspect was improved [12]. One of the reasons for the contradictory results of studies on the quality of life of mothers with GDM can be that their quality of life has been measured by a general questionnaire in these studies. Although general questionnaires are valid, they may not be suitable for measuring the quality of life of a specific community such as pregnant women or women with GDM. These questionnaires may not be sufficiently sensitive to reflect the impact of small but important interventions or treatments, and may ignore the unique viewpoints of pregnant women with or without pregnancy complications. Note that during this period, specific psychological pregnancy-related changes develop along with new concerns due to the presence of the fetus [13].

A specific quality of life questionnaire is used to examine the elements relevant to a specific disease. A specific questionnaire on the quality of life of pregnant women $[14,15]$ as well as specific quality of life questionnaire for people with diabetes [16-18] has been developed in different countries. However, no specific quality of life questionnaire has been developed for women with GDM. The specific quality of life instrument is developed for a disease, and since these instruments are sensitive in examining small but important changes in treatments and care, they can be used to examine such effects and treatments [19]. Therefore, the quality of life questionnaire for patients with GDM can provide valuable information about the factors with the greatest impact on a person and can help find the best option in the patient care (treatment and screening). Also, the members of the healthcare team can use the quality of life index to improve interaction with patients, identify the aspects of life representing the patients' major concerns, as well as developing and evaluating the measures taken based on the information obtained.

According to literature review on the quality of life of pregnant mothers with GDM, a specific study has not been performed for development and psychometric evaluation of quality of life questionnaire for women with GDM in Iran or in another country. Therefore, due to the high prevalence and growth of gestational diabetes in Iran and the importance of quality of life promotion in patients with GDM, this study aims to develop and assess the psychometric properties of quality of life questionnaire for women with GDM.

\section{Methods}

A methodological study of sequential exploratory mixed method was developed and implemented. It included qualitative (development of a quality of life questionnaire for mothers with GDM) and quantitative (assessment of psychometric prosperities of quality of life questionnaire for mothers with GDM) phases. The research setting included the healthcare centers affiliated with Shahid Beheshti University of Medical Sciences in Tehran. The study sample consisted of the pregnant women with GDM. The inclusion criteria were GDM in the current pregnancy and having no other physical and psychological disorders according to patient's statement. The sampling lasted from March 2017 to October 2018.

\section{Instrument development}

In this study, Waltz's 4 steps of instrument development (2010) were used for instrument development [20]. Also, the deductive-inductive method was used to extract items of the quality of life questionnaires for women with GDM (GDMQ-36). In order to explain the concept and dimensions of mothers' quality of life with GDM, qualitative study was performed using conventional content analysis method. For this purpose, 25 pregnant women with GDM and 8 experts were individually interviewed using an unstructured questionnaire. Experts included Obstetrician, endocrinologist, dietitian, reproductive health specialist, and midwife with at least two years of experience with GDM women.

In this study, $75 \mathrm{~g}$ OGTT were used to screening and diagnosing gestational diabetes in the 24-32 weeks of pregnancy. Gestational diabetes was being given, if one of the numbers was equal or higher than normal limit ( $\geq 92$ for fasting, $\geq 180$ and $\geq 153 \mathrm{mg} / \mathrm{dL}$ for 1 -h and 2 -h plasma glucose level, resp) [21]. This information were recorded at prenatal care.

The data was analyzed by Graneheim and Lundman's conventional content analysis method [22]. At the end 
of the qualitative phase of the study, the concept and dimensions of the quality of life of mothers with gestational diabetes were explained. In order to test the accuracy of the data, Lincoln and Guba's four criteria were used including credibility, reliability, authenticity, and transferability [23].

Subsequently, extensive literature review was conducted using the keywords "Quality of Life OR Quality of life questionnaire" AND "Gestational diabetes OR Diabetes" in Scopus, Pubmed, Science Direct, Google Scholar, SID, and Magiran databases (Table 1). The inclusion criteria were Persian or English sources, inclusion of keywords in the study, and the publication of studies in prestigious domestic or foreign journals. Accordingly, the articles published in the last thirty years were reviewed and by comparing of our extracted items and those in literature and omitting the duplicated items, the most relevant neglected items were selected by expert panel to be added to the questionnaire to improve its comprehensiveness. In this way, the initial questionnaire for assessing the psychometric properties was prepared.

\section{Psychometric properties of the instrument}

The initial questionnaire was evaluated through face validity, content validity, exploratory factor analysis with varimax rotation, convergence validity and known groups validity. On the other hand, the reliability was evaluated through internal consistency and stability of the instrument via test-retests. The details of implementation of the psychometric properties are as follows:

\section{Face validity}

In interviews, 10 women with GDM were asked first to evaluate the questions regarding their level of difficulty, irrelevancy, and ambiguity (qualitative face validity) [20]. Next, they were asked to specify the importance of the items in 5-point Likert scale (quantitative face validity). Using the impact score $=$ importance * frequency and the cut-off point of 1.5, the importance of the items was calculated and evaluated [32].

\section{Content validity}

The content validity was individually assessed by 10 specialists. A total of 10 specialists in reproductive health, midwifery, and nursing were asked to evaluate the questionnaire in terms of grammar, wording, item allocation (qualitative content validity). Also, the assessment was based on the Waltz \& Bausell content validity index (CVI) [33]; the experts scored the relevancy, clarity and simplicity of each item through a four-point Likert scale, and the CVI for each item was calculated by dividing the number of experts who scored items a 3 or 4 by the total number of experts. The statement was accepted if the
CVI was $\geq 0.79$ [33]; the necessity of the items was assessed through a three-point rating scale: (i) not necessary, (ii) useful, but not essential (iii) essential. Following the experts' assessments, a content validity ratio (CVR), for the total scale was computed. According to Lawshe, an acceptable CVR value for 10 experts was 0.62 [33]. Scale-level content validity index (S-CVI) and scale-level content validity ratio (S-CVR) was computed by calculating the mean of CVI and CVR values, where S-CVI > $0.9 \%$ is considered acceptable [34].

\section{Exploratory factor analysis}

exploratory factor analysis was performed to evaluate the validity of the instrument structure. In factor analysis,100-200 samples have been considered to be adequate [35]. Accordingly, 165 pregnant women with GDM were asked to complete the questionnaire. Multistage random sampling method was used for selecting mothers. Then, clinics from first, Eastern, Western, Northern and Southern regions of Tehran, under the coverage of Shahid Beheshti University, were classified into 4 categories. Next, from each category, a number of clinics (cluster) were randomly selected, after which inside each cluster the sample was selected based on purposive sampling in proportion to the cluster weight. After the explanation of the study objectives and obtaining informed consent, mothers with GDM completed the questionnaire if they were willing to. Kaiser-Meyer Olkin test was used to assess the sample adequacy. Eigenvalue $>=1$ and screen plot were used to determine the factors extracted. The cut-off point was considered 0.4 for the minimum factor load required to maintain the item in the factor.

\section{Convergence validity}

To assess the convergence validity, diabetes clients' quality of life questionnaire (DCQOL) was employed. After explaining the study objectives and obtaining informed consent, 85 mothers with GDM willingly completed GDMQ-36 and DCQOL questionnaires. The DCQOL questionnaire is an Iranian instrument whose validity and reliability have been validated and has five subscales including physical, mental, social, economic, and disease and treatment [18]. Then, Pearson correlation coefficient was used to examine the relationship between the five domains of GDMQ-36 and DCQOL questionnaires as well as the total scores of the two questionnaires using SPSS-21. In this study, the correlation coefficients below $0.4,0.4-0.7$, and above 0.7 were considered as low, moderate, and strong, respectively [34].

\section{Reliability}

Cronbach's coefficient alpha was used to examine the internal consistency of the subscales and the entire 
Table 1 Tools were reviewed to extract the item of quality of life questionnaire for mothers with gestational diabetes mellitus

\begin{tabular}{|c|c|c|c|c|c|c|c|c|}
\hline Title of the tool & Author-year & $\begin{array}{l}\text { Dimensions of the } \\
\text { questionnaire }\end{array}$ & $\begin{array}{l}\text { Face } \\
\text { validity }\end{array}$ & $\begin{array}{l}\text { Content } \\
\text { validity }\end{array}$ & $\begin{array}{l}\text { Factor } \\
\text { analysis }\end{array}$ & Convergence Validity & $\begin{array}{l}\text { internal } \\
\text { consistency }\end{array}$ & stability \\
\hline $\begin{array}{l}36 \text { item short form } \\
\text { survey (SF-36) [24] }\end{array}$ & $\begin{array}{l}\text { Ware and } \\
\text { Sherbourne- } \\
1992\end{array}$ & $\begin{array}{l}\mathrm{PF}_{1}^{1} \mathrm{RP}_{1}^{2} \mathrm{BP}_{1}^{3} \mathrm{GH}_{1}^{4} \\
\mathrm{VT}_{1}^{5} \mathrm{SF}_{1}^{6} \mathrm{RE}_{1}^{7} \mathrm{MH}_{1}^{8}\end{array}$ & - & - & - & - & - & - \\
\hline $\begin{array}{l}\text { World Health Organization } \\
\text { Quality Of Life Bref } \\
\text { (WHO-QOL Bref) [25] }\end{array}$ & $\begin{array}{l}\text { World health } \\
\text { organization- } \\
1992\end{array}$ & $\begin{array}{l}\text { Physical health, } \\
\text { psychological, } \\
\text { social relationship, } \\
\text { environment }\end{array}$ & - & - & - & - & - & - \\
\hline $\begin{array}{l}\text { Audit of Diabetes } \\
\text { Dependent QoL } \\
\text { (ADDQOL) [16] }\end{array}$ & Bradley-1999 & 13 item & - & - & 3 factor & - & - & - \\
\hline $\begin{array}{l}\text { diabetes quality of life } \\
\text { brief clinical inventory [26] }\end{array}$ & $\begin{array}{l}\text { Burroughs- } \\
2004\end{array}$ & $\begin{array}{l}\text { Self care behaviors, } \\
\text { satisfaction with } \\
\text { diabetes control }\end{array}$ & - & - & - & - & 0.77 & 0.72 \\
\hline $\begin{array}{l}\text { diabetes-specific quality- } \\
\text { of-life (D-QOL) scale [17] }\end{array}$ & Lee-2012 & $\begin{array}{l}\text { Emotional sufferinge, } \\
\text { Social functioninge, } \\
\text { Adherence to the } \\
\text { treatment regimene, } \\
\text { Diabetes-specific } \\
\text { symptoms }\end{array}$ & - & $\begin{array}{l}\text { Qualitative } \\
\text { validity }\end{array}$ & $\begin{array}{l}4 \text { factor } \\
\text { with } 70 \% \\
\text { variance }\end{array}$ & $\begin{array}{l}\text { moderate and } \\
\text { significant relationship } \\
\text { between the D-QOL } \\
\text { and SF-36 }\end{array}$ & $0.92 \%$ & - \\
\hline $\begin{array}{l}\text { Diabetic Clients Quality } \\
\text { Of Life (DCQOL) [18] }\end{array}$ & $\begin{array}{l}\text { Darvishpoor- } \\
2005\end{array}$ & $\begin{array}{l}\text { Physical, psycological, } \\
\text { Social, Economic, } \\
\text { Disease and treatment }\end{array}$ & - & - & $\begin{array}{l}5 \text { factor } \\
\text { with } 52 \% \\
\text { variance }\end{array}$ & $\begin{array}{l}\text { significant relationship } \\
\text { between the DCQOL } \\
\text { and SF-36 }\end{array}$ & $0.88-0.93$ & $0.86-0.90$ \\
\hline $\begin{array}{l}\text { Personal Diabetes } \\
\text { Questionnaire [27] }\end{array}$ & Stetson-2011 & $\begin{array}{l}\text { Diet knowledge and } \\
\text { skills } \\
\text { Dietary decision } \\
\text { making } \\
\text { Eating problems } \\
\text { Diet barriers } \\
\text { Problems in medication } \\
\text { used } \\
\text { Medication barriers } \\
\text { Monitoring barriers } \\
\text { Exercise barriers }\end{array}$ & - & - & - & - & - & $0.65-0.83$ \\
\hline $\begin{array}{l}\text { Diabetes Management } \\
\text { Self -Efficacy Scale [28] }\end{array}$ & Bijl-1999 & $\begin{array}{l}\text { physical exercise, } \\
\text { blood sugar, } \\
\text { nutrition general } \\
\text { and medical treatment, } \\
\text { nutrition specific } \\
\text { and weight }\end{array}$ & - & - & $\begin{array}{l}4 \text { factor } \\
\text { with } 55 \% \\
\text { variance }\end{array}$ & - & 0.81 & 0.79 \\
\hline $\begin{array}{l}\text { Diabetes Knowledge } \\
\text { Questionnaire [29] }\end{array}$ & Garcia-2001 & 24 Item & - & - & - & - & $0.73-0.84$ & - \\
\hline $\begin{array}{l}\text { Adherence in Diabetes } \\
\text { Questionnaire [30] }\end{array}$ & $\begin{array}{l}\text { Kristensen- } \\
2012\end{array}$ & 19 Item & - & - & 1 factor & $\begin{array}{l}\text { Predictive validity with } \\
\mathrm{HbA} 1 \mathrm{C}\end{array}$ & $0.82-0.86$ & - \\
\hline $\begin{array}{l}\text { Psychological Predictors } \\
\text { of Therapeutic } \\
\text { success in Diabetes } \\
\text { (PPTD) questionnaire [31] }\end{array}$ & Rotella-2014 & 19 Item & - & - & - & $\begin{array}{l}\text { Predictive validity with } \\
\text { HbA1C }\end{array}$ & 0.63 & - \\
\hline
\end{tabular}

\footnotetext{
'Physical functioning

${ }^{2}$ role limitations due to physical problems

3bodily pain

${ }^{4}$ general health perceptions

${ }^{5}$ vitality

${ }^{6}$ social functioning

${ }^{7}$ role limitations due to emotional problems

${ }^{8}$ perceived mental health
}

instrument. Values above 0.79 are considered acceptable in descriptive studies [36]. Instrument stability was assessed by the test-retest method and through the completion of the questionnaires by 15 women with GDM within a two-week interval. Intra-class correlation (ICC) was utilized to assess the reliability. If the intra- 
class correlation is above 0.7 , the stability is considered desirable [37].

\section{Statistical analysis}

Data analysis was performed using SPSS-21. Data analysis was conducted through exploratory factor analysis by principal component method with varimax rotation. Normal distribution of the data was verified using Kolmogorov-Smirnov test. Cronbach's coefficient alpha and ICC were also calculated. $P$ value $<0.05$ was considered significant.

Figure 1 displays the development and psychometric properties of quality of life questionnaire for women with GDM.

\section{Ethical considerations}

Proposal of the present study was approved by the ViceChancellor of the Faculty of Nursing and Midwifery of Shahid Beheshti University of Medical Sciences. The research project was approved by the code of IR.SBMU.PHNM.1395.494 at the Ethics Committee of Shahid Beheshti University of Medical Sciences. Prior to the beginning of the study, the consent of the relevant authorities was obtained. At the beginning of the interviews, purpose of the research, interview method, data confidentiality, and the freedom of choice to enter or quit the study were explained to the participants and their informed consent was obtained.

\section{Results}

\section{Development of a primary questionnaire}

The findings of qualitative study indicated that the quality of life of mothers with GDM is a multidimensional concept. GDM affects different aspects of health and life of mothers suffering from it and leads to physical and psychological problems. Mothers with GDM perceive some limitations like social isolation and playing their maternal and spousal roles or some restrictions as a result of their treatment procedures. In addition, these mothers perceive their pregnancy as high risk because are worried about the outcomes of this disease and concerns about treatment and healthcare service. Using some procedures like adaptation, support and self-care to confront such restrictions and concerns result in coping with this disease. Content analysis led to the extraction of 4 themes including: 1- complications of gestational diabetes (physical and psychological disorders), 2-perceived constraints (social isolation, role playing, and inflexible pregnancy due to treatments), 3-concerns about high risk pregnancy (concern for outcome Disease and treatment) and 4-coping strategies (adjustment, protection and self-care).

Based on the findings of the qualitative phase and literature review, primary question pool of the questionnaire was extracted including 133 items from findings of the qualitative phase of the study and 9 items from the literature review (Table 2). Accordingly, the primary questionnaire was prepared with 142 items. The distribution of 142 items in the questionnaire was as follows: complications of GDM (15 items), perceived constraints (29 items), concerns about high-risk pregnancy (32 items), and coping strategies (66 items). Each item was scored based on5-point Likert scale (strongly agree to strongly disagree) or (always to never).

\section{Face validity}

Demographic information on patients participated in the face validity are shown in Table 3 . In qualitative face

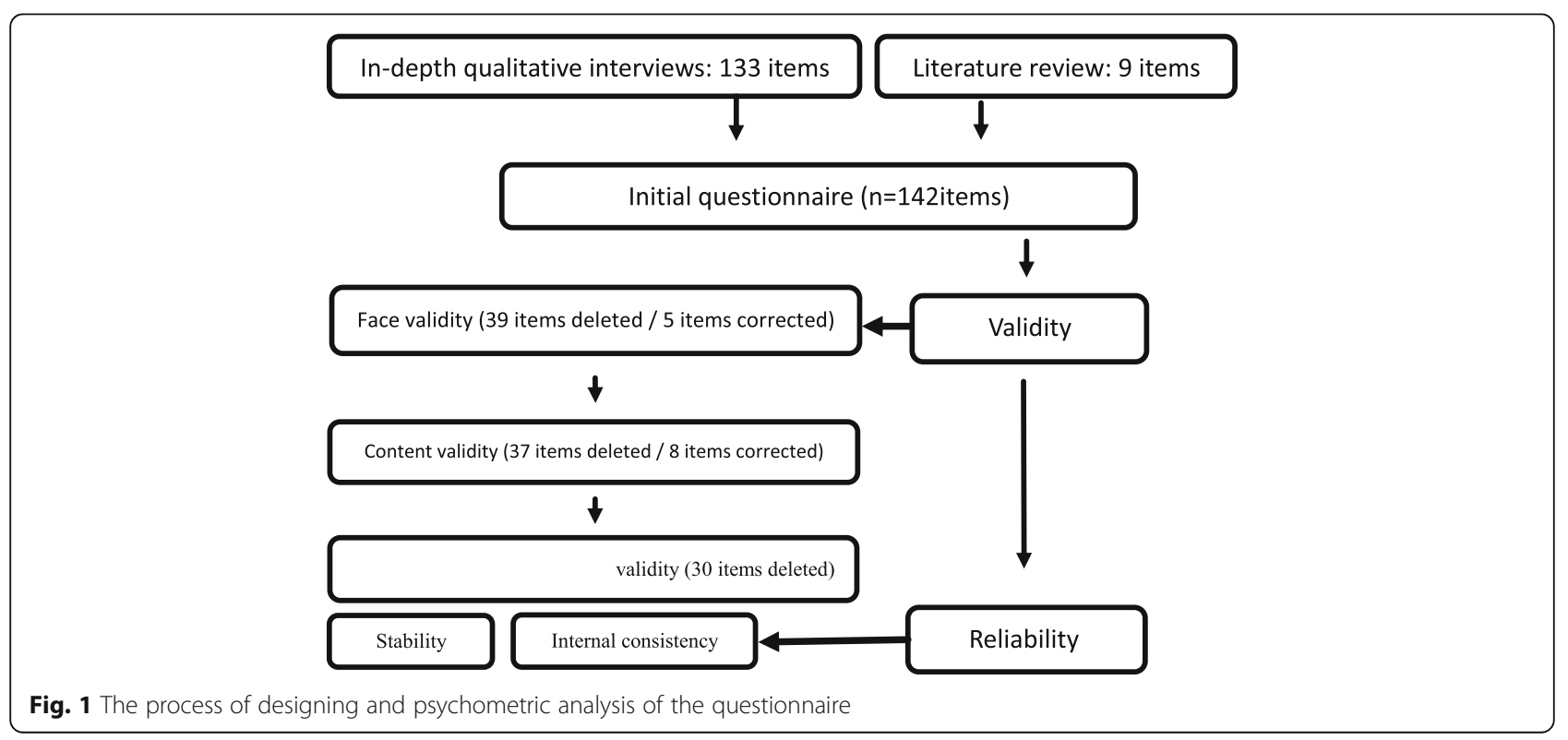


Table 2 Extracted items from the review of the literature to design a questionnaire on "quality of life of mothers with gestational diabetes mellitus"

I prefer to eat something I shouldn't, rather than tell someone that I have diabetes [26]

I'm worried about whether I will miss work [26]

I feel diabetes limits my career [26]

I feel satisfied with my blood glucose control [28]

Recording your blood glucose levels in your chart/diabetes diary when your health care personnel

asks you to [30]

I adjust insulin dose based on my blood glucose [30]

My diet is repetitious and not diversified [38]

Gestational diabetes has caused me not to enjoy my pregnancy [39]

I feel that my pregnancy is an abnormal pregnancy [40] validity, according to the participants' comments (10 pregnant women with GDM), a number of items were corrected. In the quantitative face validity, on the other hand, 39 items were eliminated with a cut-off point of 1.5 as an acceptable impact score to maintain the item (reducing 142 to 103 items).

\section{Content validation}

In the qualitative content validity, according to the suggestions of experts (10 specialist), some items were revised, at which phase 5 items related to costs were summed up in 1 item, whereby the number of the items reduced from 103 to 99 . In the quantitative content analysis, the Content Validity Ratio (CVR) and Content Validity Index (CVI) were calculated for each item, and considering the appropriate cut-off point, the number of

Table 3 Demographic characteristics of women with GDM that participated in psychometric testing steps

\begin{tabular}{|c|c|c|c|c|c|}
\hline Characteristics & Face validity $(n=10)$ & $\begin{array}{l}\text { Factor analysis } \\
\text { And } \\
\text { Known group validity } \\
(n=165)\end{array}$ & $\begin{array}{l}\text { Convergence validity } \\
(n=85)\end{array}$ & $\begin{array}{l}\text { Internal consistency } \\
(n=30)\end{array}$ & $\begin{array}{l}\text { Stability } \\
(n=15)\end{array}$ \\
\hline \multicolumn{6}{|l|}{ Age (years) } \\
\hline Mean (SD) & $29.6(4.69)$ & $31.79(5.30)$ & $29.87(5.33)$ & $28.20(5.88)$ & $28.40(5.91)$ \\
\hline Range & $23-38$ & $19-44$ & $19-40$ & 19-39 & $20-38$ \\
\hline \multicolumn{6}{|l|}{ Gestational age (weeks) } \\
\hline Mean (SD) & $30.80(3.76)$ & $31.00(3.52)$ & $30.40(3.74)$ & $31.33(3.72)$ & $31.2(3.70)$ \\
\hline Range & $27-36$ & $26-39$ & $26-39$ & $26-37$ & $26-36$ \\
\hline \multicolumn{6}{|l|}{ Level of education } \\
\hline Elementary & $6(60 \%)$ & $67(40.6 \%)$ & $21(24.7 \%)$ & $12(40 \%)$ & $7(46 \%)$ \\
\hline High school & $2(20 \%)$ & $60(36.4 \%)$ & $36(42.4 \%)$ & $10(33.3 \%)$ & $5(33 \%)$ \\
\hline College/university & $2(20 \%)$ & $31(18.8 \%)$ & $23(27.1 \%)$ & $8(26.7 \%)$ & $3(20 \%)$ \\
\hline postgraduate & $0(0 \%)$ & $7(4.2 \%)$ & $5(5.9 \%)$ & $0(0 \%)$ & $0(0 \%)$ \\
\hline \multicolumn{6}{|l|}{ Employment status } \\
\hline Employment & $8(80 \%)$ & $18(10.9 \%)$ & $12(14.1 \%)$ & $4(13.3 \%)$ & $2(13.3 \%)$ \\
\hline Housekeeper & $2(20 \%)$ & $147(89.1 \%)$ & 73 (85.9\%) & $26(86.7 \%)$ & $13(86.7 \%)$ \\
\hline \multicolumn{6}{|l|}{ Economic status } \\
\hline Poor & $4(40 \%)$ & $64(38.8 \%)$ & $23(27.1 \%)$ & $12(40 \%)$ & $6(40 \%)$ \\
\hline Moderate & $5(50 \%)$ & 79 (47.9\%) & $48(56.5 \%)$ & $15(50 \%)$ & $9(60 \%)$ \\
\hline good & $1(10 \%)$ & $22(13.3 \%)$ & $14(16.5 \%)$ & $3(10 \%)$ & $0(0 \%)$ \\
\hline \multicolumn{6}{|l|}{ Gravida } \\
\hline nuliparus & $4(40 \%)$ & 49 (29.7\%) & $37(43.5 \%)$ & $10(33.3 \%)$ & $2(13.3 \%)$ \\
\hline multiparus & $6(60 \%)$ & $116(70.3 \%)$ & $48(56.5 \%)$ & $20(66.6 \%)$ & $13(86.7 \%)$ \\
\hline \multicolumn{6}{|l|}{ Hospitalization } \\
\hline Yes & $3(30 \%)$ & $63(38.2 \%)$ & $28(32.9 \%)$ & $11(36.7 \%)$ & $4(26.7 \%)$ \\
\hline no & 7 (70\%) & $102(61.8 \%)$ & $57(67.1 \%)$ & 19 (63.3\%) & $11(73.3 \%)$ \\
\hline \multicolumn{6}{|l|}{ Treatment } \\
\hline Diet & $7(70 \%)$ & 79 (47.9\%) & 47 (55.3\%) & 17 (56.7\%) & $11(73.3 \%)$ \\
\hline Medical treatment & $3(30 \%)$ & $86(52.1 \%)$ & $38(44.7 \%)$ & $13(43.3 \%)$ & $4(26.7 \%)$ \\
\hline
\end{tabular}


items was curtailed from 103 to 66, with S-CVI and SCVR obtained as 0.99 and 0.73 , respectively.

\section{Factor analysis}

For exploratory factor analysis, 165 women with GDM completed a 66-item questionnaire. Demographic information on patients participated in the factor analysis are shown in Table 3. The recommended number of respondents for factor analysis is between 100 and 200 subjects [41]. The value of 0.80 obtained from KMO test and the significance of the Bartlett test results $(p<0.001)$ suggested that the sampling was adequate. In the exploratory factor analysis, considering 0.4 as the minimum factor load, 30 items were deleted, with 36 items left. Decision on the number of factors for rotation was based on the special value of above 1 , with 10 factors accounting for $61.71 \%$ of the observed variance; which seems high considering the theoretical basis. Accordingly, five factors were considered as defaults in factor analysis to simplify and make the constructive factors of the instrument developed interpretable, and given the low explaining power of the last factors, taking into account the consistency of the extracted factors with the concept and dimensions of the quality of life of mothers with GDM.

Factor analysis with 5 constant factors was repeated with varimax rotation. Based on the 5 constant factors, $46.68 \%$ of variance was explained. The highest variance was assigned to the factor 1 (concerns related to high risk pregnancy), while the minimum variance was related to factor 5 (support) (Table 4).

Based on factor analysis, 5 factors were extracted for the quality of life questionnaire for women with GDM (Table 5). As shown in Table 5, some of the items with different factor loads are placed across several factors. Although it was attempted to place the items in factors with the largest factor load, the item "I'm concerned about delayed wound healing" was passed to a factor with a lower factor load since it was not consistent the factor with the highest factor load. The items that were not loaded on any of the factors were excluded from the questionnaire whereby the questionnaire was reduced to 36 questions. Subsequently, considering the research team's commentary, each factor was named according to its items. The 5 factors in quality of life questionnaire for women with GDM included concerns about highrisk pregnancy (11 items), perceived constraints (8 items), GDM complications (6 items), medication and treatment (5 items), and support (6 items).

\section{Convergence validity}

To assess the convergence validity, the quality of life questionnaire for women with GDM and Diabetes Clients Quality Of Life questionnaire were completed by 85 pregnant women with GDM. Demographic information on patients participated in the convergence validity are shown in Table 3. The correlation between the scores of the different domains of the two questionnaires and the correlation of the two questionnaires were examined via Pearson test (Table 6). The results showed a moderate and significant relationship between the total score of the two questionnaires $(r=0.64)$.

\section{Reliability}

Demographic information on patients participated in the reliability are shown in Table 3 . The internal consistency of the questionnaire was evaluated using the Cronbach's coefficient alpha. The coefficient of 0.93 for the entire instrument and coefficients of 0.77 to 0.90 for the subscales showed proper internal consistency. Tool stability was tested by a test-retest method via intra-class correlation coefficient. ICC of 0.95 for the entire instrument and coefficients of 0.85 to 0.98 for sub-scales revealed acceptable stability of the questionnaire (Table 7).

After evaluation of the validity and reliability, the final questionnaire quality of life on GDM (GDMQ-36) was developed with 36 items and 5 factors including "concerns about high-risk pregnancy", "perceived restrictions", "disease complications", "medication and treatment" and "support" (Table 8).

\section{Scoring procedure}

The final questionnaire for quality of life of mothers with GDM consists of 36 questions in 5 domains, based on 5point Likert scale (strongly agree to strongly disagree) with a score range of 1 to 5 . This procedure is used for the items in the domains of concerns about high-risk pregnancy, perceived constraints, complications of GDM, and

Table 4 Initial eigenvalues for the Quality Of Life Questionnaire for women with Gestational Diabetes Mellitus

\begin{tabular}{|c|c|c|c|c|c|c|c|c|c|}
\hline \multirow[t]{2}{*}{ Component } & \multicolumn{3}{|c|}{ Initial Eigenvalues } & \multicolumn{3}{|c|}{ Extraction Sums of Squared Loadings } & \multicolumn{3}{|c|}{ Rotation Sums of Squared Loadings } \\
\hline & Total & $\%$ of Variance & $\%$ Cumulative & Total & $\%$ of Variance & $\%$ Comulative & Total & $\%$ of Variance & $\%$ Comulative \\
\hline 1 & 8.49 & 22.96 & 22.96 & 8.49 & 22.96 & 22.96 & 5.51 & 14.90 & 14.90 \\
\hline 2 & 2.57 & 6.95 & 29.91 & 2.57 & 6.95 & 29.91 & 3.62 & 9.78 & 24.69 \\
\hline 3 & 2.49 & 6.74 & 36.65 & 2.49 & 6.74 & 36.65 & 2.86 & 7.73 & 32.42 \\
\hline 4 & 2.03 & 5.49 & 42.14 & 2.03 & 5.49 & 42.14 & 2.68 & 7.26 & 39.68 \\
\hline 5 & 1.67 & 4.53 & 46.68 & 1.67 & 4.53 & 46.68 & 2.58 & 6.99 & 46.68 \\
\hline
\end{tabular}


Table 5 Matrix of Rotated Factors with Varimax Rotation and Factor Load rates of Items in Each Factor for the Quality Of Life Questionnaire for women with Gestational Diabetes Mellitus

\begin{tabular}{|c|c|c|c|c|c|c|}
\hline \multirow[t]{2}{*}{ Raw } & \multirow[t]{2}{*}{ Item } & \multicolumn{5}{|c|}{ Factor load } \\
\hline & & 1 & 2 & 3 & 4 & 5 \\
\hline 1 & I'm concerned about premature birth of my baby & 0.846 & & & & \\
\hline 2 & I'm concerned about the loss of fetal movement & 0.795 & & & & \\
\hline 3 & I'm concerned about the fetal death & 0.775 & & & & \\
\hline 4 & I'm concerned about fetal abnormalities & 0.765 & & & & \\
\hline 5 & $\begin{array}{l}\text { I'm concerned about my baby's blood sugar } \\
\text { drop after birth }\end{array}$ & 0.655 & & & & \\
\hline 6 & I have to visit doctors with different specialties & 0.601 & & & & \\
\hline 7 & I'm concerned about poor weight gain & 0.572 & & & & \\
\hline 8 & $\begin{array}{l}\text { I'm concerned that diabetes would be transmitted } \\
\text { to my baby }\end{array}$ & 0.558 & & & & \\
\hline 9 & I have to visit the doctor frequently & 0.554 & & & & \\
\hline 10 & I'm concerned about fetal and baby weight gain & 0.524 & & & & \\
\hline 11 & I'm concerned about delayed wound healing & 0.436 & & & 0.439 & \\
\hline 12 & My diet is repetitious and not diversified & & 0.721 & & & \\
\hline 13 & I faced constraints on my favorite foods and fruits & & 0.705 & & & \\
\hline 14 & My food is separated from the family meal & & 0.612 & & & \\
\hline 15 & The family basket has changed due to my diet & & 0.524 & & & \\
\hline 16 & $\begin{array}{l}\text { To measure fasting blood sugar, I should fast for a } \\
\text { long time and endure hunger }\end{array}$ & & 0.518 & & & \\
\hline 17 & My sexual activity has decreased due to GDM & & 0.480 & & & \\
\hline 18 & I use fruits and food with low and determined amounts & & 0.457 & & & \\
\hline 19 & I go less often to the party and restaurants due to GDM & & 0.401 & & & \\
\hline 20 & I have feelings of thirst and dry mouth & & & 0.731 & & \\
\hline 21 & I repeatedly go to the bathroom & & & 0.695 & & \\
\hline 22 & I have blood sugar drop & & & 0.628 & & \\
\hline 23 & I get angry soon & & & 0.580 & & \\
\hline 24 & I feel depressed & & & 0.579 & & \\
\hline 25 & My mind is obsessed with the disease & & 0.414 & 0.465 & & \\
\hline 26 & $\begin{array}{l}\text { Insulin injection is difficult for me at specific times } \\
\text { of the day }\end{array}$ & & & & 0.760 & \\
\hline 27 & $\begin{array}{l}\text { Insulin injections for several times is difficult and } \\
\text { time consuming for me }\end{array}$ & & & & 0.755 & \\
\hline 28 & Frequent blood glucose test is difficult for me & & & & 0.510 & \\
\hline 29 & I'm concerned about drug side effects on my fetus & & & & 0.508 & \\
\hline 30 & I adjust insulin dose based on my blood glucose & & & & 0.499 & \\
\hline 31 & People's empathy helps me to tolerate the disease & & & & & 0.678 \\
\hline 32 & $\begin{array}{l}\text { My spouse mental and emotional support helps me } \\
\text { tolerate the disease easier }\end{array}$ & & & & & 0.671 \\
\hline 33 & $\begin{array}{l}\text { The information from healthcare workers about the } \\
\text { disease has helped me }\end{array}$ & & & & & 0.605 \\
\hline 34 & $\begin{array}{l}\text { The positive experience of the people around me about } \\
\text { the disease has helped me }\end{array}$ & & & & & 0.594 \\
\hline 35 & $\begin{array}{l}\text { The information I receive about the disease from the } \\
\text { media and the Internet has helped me }\end{array}$ & & & & & 0.560 \\
\hline 36 & Prayer with God has helped me tolerate the disease & & & & & 0.431 \\
\hline
\end{tabular}


Table 6 Correlation Coefficient between the GDMQ-36 factors and the DCQOL subscales $(n=85)$

\begin{tabular}{|c|c|c|c|c|c|c|}
\hline \multirow[t]{2}{*}{ Subscales of questionnaire } & & \multirow[b]{2}{*}{ Physical } & \multicolumn{4}{|c|}{ Diabetes Clients Quality Of Life questionnaire (DCQOL) } \\
\hline & & & Psychological & Social & Economic & $\begin{array}{l}\text { Disease and } \\
\text { treatment }\end{array}$ \\
\hline \multirow{5}{*}{$\begin{array}{l}\text { Gestational Diabetes Mellitus Quality } \\
\text { Of Life-36 Item } \\
\text { (GDMQ-36) }\end{array}$} & $\begin{array}{l}\text { concerns about high-risk } \\
\text { pregnancy }\end{array}$ & 0.04 & 0.14 & -0.04 & 0.06 & $0.39^{* *}$ \\
\hline & perceived constraints & -0.02 & 0.10 & -0.18 & -0.006 & $0.67^{* *}$ \\
\hline & GDM complications & 0.14 & $0.65^{* *}$ & 0.11 & $0.21^{*}$ & $-0.13^{* *}$ \\
\hline & medication and treatment & 0.10 & -0.01 & 0.005 & -0.05 & $0.46^{* *}$ \\
\hline & support & 0.06 & 0.005 & $-0.43^{* *}$ & -0.06 & 0.04 \\
\hline
\end{tabular}

*Significant at the $p<0.05$

**Significant at the $p<0.01$

medication and treatment, with the exception of item 29 , "I adjust insulin dose based on my blood glucose"(strongly agree $=1$, strongly disagree $=5$ ). In the domain of support, the answer "strongly agree" scores 5 while the answer "strongly disagree" scores 1 . Mothers who do not receive insulin,scores of these questions is considered 3(have no idea) .

The total score of the questionnaire, based on the above explanations is 36-180, with higher scores indicating greater quality of life. Due to the diversity of the domains studied and the response scales chosen for each domain, a standardization method of 0 to 100 was used for better understanding the scoring procedure and comparison of the questionnaire's different sub-scale scores. To convert the scores of the sub-scales and the entire questionnaire to a score of 0 to 100 , the following conversion formula was used.

Adjusted score $=$ (acquired raw score/maximum possible score)* 100 .

Using this formula, a score of 0 to 100 is obtained in each of the sub-scales. Higher scores represent a better status in the subscale. The total score of the instrument is computed by calculating the average of the total modified scores of the instrument. Higher scores in the entire instrument represent better quality of life. Score range of questionnaire for quality of life of mothers with GDM (GDMQ-36) are shown in Table 9.

Table 7 Reliability measures for the GDMQ-36

\begin{tabular}{lll}
\hline subscales & $\begin{array}{l}\text { Cronbach's } \\
\text { alpha }\end{array}$ & $\begin{array}{l}\text { intra-class correlation } \\
\text { coefficient (ICC) }\end{array}$ \\
\hline $\begin{array}{l}\text { concerns about high-risk } \\
\text { pregnancy }\end{array}$ & 0.90 & 0.98 \\
perceived constraints & 0.80 & 0.95 \\
GDM complications & 0.85 & 0.90 \\
medication and treatment & 0.77 & 0.85 \\
support & 0.84 & 0.92 \\
Total & 0.93 & 0.95 \\
\hline
\end{tabular}

\section{Discussion}

In this study, using a qualitative and quantitative approach, a valid, reliable, and practical questionnaire was developed for assessing the quality of life of women with GDM (GDMQ-36). In this questionnaire, the quality of life of mothers with GDM was influenced by concerns about high-risk pregnancy (11 items), perceived constraints (8 items), complications of GDM (6 items), medication and treatment (5 items), and support (6 items).

One of the most important factors in GDMQ-36 questionnaire is high-risk pregnancy related concerns, which claimed the highest percentage of variance among the tool's factors. Most of the items in this factor are concerns about the fetal health or baby health, and the most frequent factor load is the concern about the premature birth and reduced fetal movements. In various studies, concerns about neonatal health before and after birth such as preterm labor or constraints on fetal development and mortality have been raised and most of the mothers are mainly concerned about the fetal and neonatal health [42-44].

Another factor of the GDMQ-36 questionnaire was perceived constraints. The most frequent factor load in this factor was dietary constraints including limited diet diversity and constraints on favorite fruits and foods. In the qualitative study, most participants found it confusing and frustrating that they could only eat a very small portion at once, or could not eat particular fruits at all which they enjoyed prior to being diagnosed with GDM [38]. These constraints are specific to mothers with GDM who have to follow a special diet and the treatment to maintain their own and the fetal health. Such constraints can affect the quality of life of mothers with GDM. Among other constraints in GDMQ-36 questionnaire are sexual constraints which can affect the quality of life of mothers with GDM. Hyperglycemia can result in elevated serum prolactin levels and lead to neurotransmitter changes, which are potentially related to sexual dysfunction. Other causes of sexual dysfunction in these women may be the stress and anxiety sufferance because of GDM diagnosis [45]. 
Table 8 Final questionnaire quality of life on GDM (GDMQ-36)

\begin{tabular}{|c|c|c|c|c|c|c|}
\hline \multicolumn{2}{|c|}{ After Gestational Diabetes Mellitus } & \multirow{2}{*}{\multicolumn{2}{|c|}{ strongly disagree }} & \multirow[t]{2}{*}{ have no idea } & \multirow[t]{2}{*}{ agree } & \multirow[t]{2}{*}{ strongly agree } \\
\hline 1 & I'm concerned about premature birth of my baby & & & & & \\
\hline 2 & I'm concerned about the loss of fetal movement & & & & & \\
\hline 3 & I'm concerned about the fetal death & & & & & \\
\hline 4 & I'm concerned about fetal abnormalities & & & & & \\
\hline 5 & I'm concerned about my baby's blood sugar drop after birth & & & & & \\
\hline 6 & I have to visit doctors with different specialties & & & & & \\
\hline 7 & I'm concerned about poor weight gain & & & & & \\
\hline 8 & I'm concerned that diabetes would be transmitted to my baby & & & & & \\
\hline 9 & I have to visit the doctor frequently & & & & & \\
\hline 10 & I'm concerned about fetal and baby weight gain & & & & & \\
\hline 11 & I'm concerned about delayed wound healing & & & & & \\
\hline 12 & My diet is repetitious and not diversified & & & & & \\
\hline 13 & I faced constraints on my favorite foods and fruits & & & & & \\
\hline 14 & My food is separated from the family meal & & & & & \\
\hline 15 & The family basket has changed due to my diet & & & & & \\
\hline 16 & $\begin{array}{l}\text { To measure fasting blood sugar, I should fast for a long time and } \\
\text { endure hunger }\end{array}$ & & & & & \\
\hline 17 & My sexual activity has decreased due to GDM & & & & & \\
\hline 18 & I use fruits and food with low and determined amounts & & & & & \\
\hline 19 & I go less often to the party and restaurants due to GDM & & & & & \\
\hline 20 & I have feelings of thirst and dry mouth & & & & & \\
\hline 21 & I repeatedly go to the bathroom & & & & & \\
\hline 22 & I have blood sugar drop & & & & & \\
\hline 23 & I get angry soon & & & & & \\
\hline 24 & I feel depressed & & & & & \\
\hline 25 & My mind is obsessed with the disease & & & & & \\
\hline 26 & Insulin injection is difficult for me at specific times of the day & & & & & \\
\hline 27 & $\begin{array}{l}\text { Insulin injections for several times is difficult and time consuming } \\
\text { for me }\end{array}$ & & & & & \\
\hline 28 & Frequent blood glucose test is difficult for me & & & & & \\
\hline 29 & I'm concerned about drug side effects on my fetus & & & & & \\
\hline 30 & I adjust insulin dose based on my blood glucose & & & & & \\
\hline 31 & People's empathy helps me to tolerate the disease & & & & & \\
\hline 32 & $\begin{array}{l}\text { My spouse mental and emotional support helps me tolerate the } \\
\text { disease easier }\end{array}$ & & & & & \\
\hline 33 & $\begin{array}{l}\text { The information from healthcare workers about the disease has } \\
\text { helped me }\end{array}$ & & & & & \\
\hline 34 & $\begin{array}{l}\text { The positive experience of the people around me about the } \\
\text { disease has helped me }\end{array}$ & & & & & \\
\hline 35 & $\begin{array}{l}\text { The information I receive about the disease from the media and } \\
\text { the Internet has helped me }\end{array}$ & & & & & \\
\hline 36 & Prayer with God has helped me tolerate the disease & & & & & \\
\hline
\end{tabular}

Another factor in GDMQ-36 questionnaire is the disease complications including physical and psychological complications. Complications of gestational diabetes are the negative changes in various aspects of the person's health caused by the disease, which can reduce the mothers' quality of life. Due to the multidimensionality 
Table 9 Score range of questionnaire for quality of life of mothers with GDM (GDMQ-36)

\begin{tabular}{|c|c|c|}
\hline Domains & Score range & Adjusted score \\
\hline $\begin{array}{l}\text { Concerns about high-risk } \\
\text { pregnancy }\end{array}$ & $11-55$ & $\begin{array}{l}\text { (acquired raw score/maximum } \\
\text { possible score)*100 }\end{array}$ \\
\hline Perceived constraints & $8-40$ & \\
\hline Complications of GDM & $8-30$ & \\
\hline $\begin{array}{l}\text { Medication and } \\
\text { treatment }\end{array}$ & $5-25$ & \\
\hline Support & $6-30$ & \\
\hline Total & $36-180$ & \\
\hline
\end{tabular}

of quality of life, poor physical and mental health can affect the quality of life. The most frequent factor load in this factor was related to physical complications such as thirst and dry mouth and frequent urination. In a study examining the clinical and laboratory symptoms of glucose tolerance, over-hydration and frequent urination were the most important findings [46].

Another factor in GDMQ-36 questionnaire is medication and treatment. When the blood glucose cannot be controlled by diet, mothers have to administer insulin injections. The most frequent factor load in this structure was the problem of insulin injections. Repeated and timely injections of insulin, and frequent blood glucose tests in the laboratory or by a glucose meter require time management and can affect the mothers' quality of life. In a study, most participants felt that they were controlled by the diabetes and they are entrapped in a compulsory lifestyle. This compulsory life-style involved continuous monitoring of blood glucose, insulin infusion, and insulin dose adjustment [47]. This change in the lifestyle that is unfamiliar and sometimes unwanted can affect the quality of life of mothers with GDM. This has been considered in the domain of medication and treatment of GDMQ-36 questionnaire.

The last factor in GDMQ-36 questionnaire is support. The most frequent factor load in this factor is the empathy of the intimates and full support of the spouse. The support of friends and family members for mothers with GDM is effective in choosing a healthy lifestyle [48]. In the study of Han et al., the first requirement for mothers with GDM to face the disease problems was the family or spouse support [49]. Therefore, the domain of support in GDMQ-36 questionnaire may improve the quality of life of mothers with GDM.

Evaluating and recording health-centered quality of life based on quality of life assessment questionnaires has been of great importance. In previous studies, only general quality of life assessment questionnaires such as SF36 and WHO-QOL-Bref have been used to assess the quality of life of mothers with GDM [10-12]. Factor Comparison of GDM-36 questionnaire with general questionnaires suggested that GDM-36 factors are similar to some aspects of WHOQOL-Bref [25] and SF-36 [24], especially the mental and social health aspects. Although some of the items in GDMQ-36 questionnaire are consistent with the general questionnaire, the nature of the items in the general questionnaire is different from that of the questionnaire developed in this study. Specifically, the items in GDMQ-36 questionnaire are all in the context of GDM, but the items in the general questionnaires are designed in a way to be applicable to all communities. Public questionnaires (such as SF-36) are designed with no regard to the unique experiences of pregnancy. Although there are studies that show the adequacy of these questionnaires for different communities, their adequacy for the pregnant population has not been determined [13]. In their study, Otchet et al. stated that the SF-36 health questionnaire of pregnant women has some constraints [50].

Other specific questionnaires, in this regard, include the pregnant women's quality of life and diabetes' quality of life questionnaire.

The pregnant women's quality of life questionnaire (QOL-GRAV) is an instrument with 9 questions originally developed in Czech Republic. According to its designers, it is a supplementary tool for the general quality of life questionnaire of World Health Organization (WHO) [15]. Comparison of this tool with GDM-36 questionnaire revealed that QOL-GRAV could not be potentially suitable for the quality of life assessment of mothers with GDM as it ignores many concerns and constraints which can affect the quality of life of mothers with GDM. In thin questionnaire, there is only one question, i.e. "How concerned are you about carrying a successful pregnancy?" that can be partly consistent with the domain "Concerns about high-risk pregnancy" in GDM-36 questionnaire. Another questionnaire on pregnant women's quality of life has been developed in Iran which includes 65 questions in three domains of physical, psychological, and social problems; concern and worries; and adaptation [14]. During pregnancy, physiologically due to hormonal changes, some physical or psychological complications occur in pregnant mothers. These issues have been addressed in this questionnaire, but the complications assessed in GDM36 are the result of the increased or decreased blood glucose levels. The domain of concerns and worries in the pregnant women's quality of life questionnaire, in some cases, were similar to concerns about high-risk pregnancy in GDM-36 questionnaire. However, in the pregnant women's quality of life questionnaire, most concerns were about childbirth than the fetal health, as pregnant mothers' quality of life questionnaire is only suitable for mothers who have a healthy and safe pregnancy. 
Audit of Diabetes-Dependent Quality Of Life (ADDQOL) is a 13-item questionnaire developed by Bradley et al. [16]. Also, Diabetes Quality of Life (DQOL) questionnaire has 16 questions developed by Lee et al. [17].Since diabetes is a chronic disease and can have a major impact on the social dimension and longterm consequences on the life of the patients, the questionnaire questions are more about social problems or long-term concerns of the disease. Therefore, these questionnaires may not be able to assess the pregnant mothers' quality of life, especially those diagnosed with diabetes during the pregnancy.

The face, content, exploratory factor analysis, and reliability are required to assess psychometric properties of a questionnaire [20]. In this study, qualitative and quantitative face validity, qualitative and quantitative content validity, exploratory factor analysis, convergence validity, and reliability were evaluated for GDMQ-36 questionnaire. For its face validity, after correcting the ambiguous items, the impact factor was calculated for each item, where items with impact factor of less than 1.5 were omitted. In content validity, CVR and CVI were calculated for each item, where items with CVR of less than 0.62 and CVI of less than 0.79 were removed, after consultation with the research team. The review of the items deleted in face and content validity evaluation phase indicated that their concepts were explained by the remaining variables. S-CVI was equal to 0.99 demonstrating that the entire tool has a desirable and robust strong validity [34].

Exploratory factor analysis was used for validity of GDMQ-36 questionnaire. Factor analysis is performed in two general forms called exploratory and confirmatory factor analysis. The confirmatory factor analysis is used to confirm previous work. In exploratory factor analysis, the researcher seeks to discover the underlying structure of a relatively large set of variables, with the initial assumption being that each variable may be related to each of the factors. In other words, the researcher has no initial theory in this method [34]. In exploratory factor analysis of GDMQ-36, five factors explained $46.68 \%$ of the total variance of the questionnaire through exploratory factor analysis.

Diabetes clients' quality of life (DCQOL) questionnaire was used for convergent validity of GDMQ-36 questionnaire. Since there was no quality of life questionnaire for women with GDM, diabetes' quality of life questionnaire was used. Among the diabetes' quality of life questionnaires, Diabetes clients' quality of life (DCQOL) questionnaire proved to be more appropriate, since this questionnaire was developed and assessed regarding its psychometric properties in Iran [18] and has been closer to GDMQ-36 questionnaire in terms of culture. Statistical analysis showed a moderate and significant relationship between the two questionnaires which was acceptable [51]. Factors of concerns about high-risk pregnancy, perceived constraints, as well as medication and treatment in GDMQ-36 questionnaire had a significant relationship with factors of disease and treatment in the DCQOL questionnaire. Comparison of the items of these factors revealed that the concept of some items of the disease and the treatment factor in the DCQOL questionnaire existed in the three domains of GDMQ-36 questionnaire. However, the items of DCQOL questionnaire captured more general concerns and did not take into account pregnancy concerns. The disease complications of GDMQ-36 questionnaire had a significant correlation with the psychological domain of the DCQOL questionnaire, while the physical complications of the DCQOL questionnaire included those more related to the physical problems of chronic diseases. The support factor of our questionnaire had a significant and inverse relationship with the social domain of the DCQOL questionnaire. Specifically, in our questionnaire, the items about support were positive while in the DCQOL questionnaire, the items associated with support were negative, and it was of the long-term social complications of the disease.

One strong point of this study was the use of exploratory mixed methods including qualitative and quantitative phases for development and assessment of psychometric properties of the questionnaire. The participants of this study were mothers suffering GDM with the highest diversity in age, education, economic status, gestational age, and type of treatment (diet or insulin, inpatient or outpatient treatment).This makes it easier to evaluate the quality of life of mothers with GDM through GDMQ-36 questionnaire. Nevertheless, this study had also some limitations. The most important was that the questionnaire was developed in Iran, thus requiring translation and revalidation in other communities. It seems that a welldesigned questionnaire can be used in various communities after being fully translated and evaluated by the professionals in those communities [52].

\section{Conclusion}

GDMQ-36 is a simple, valid, and reliable tool for assessing the quality of life of women with GDM. GDMQ-36 may help healthcare providers and health policy makers to identify and assess the different dimensions of quality of life of mothers with GDM and to adapt their measures to improve the health and quality of life of these mothers. Different screening and treatment methods have been proposed for GDM. Policymakers can use this questionnaire to compare different types of GDM screening methods or different therapeutic approaches (diet, drug administration, oral medications), and use a method for screening and treatment with the minimum effect on these mothers' quality of life. 


\section{Abbreviations}

ADDQOL: Audit of Diabetes-Dependent Quality Of Life; CVl: Content Validity Index; CVR: Content Validity Ratio; DCQOL: Diabetic Clients Quality Of Life; DQOL: Diabetes Quality of Life; GDM: Gestational Diabetes Mellitus; GDMQ36: Gestationla Diabetes Mellitus Quality of life questionnair 36 item; ICC: Intra-Class Correlation; OGTT: Oral Glucose Tolerance Test; QALY: Quality Adjusted Life Years; QOL-GRAV: Pregnant women's quality of life questionnaire; S-CVI: Scale-level Content Validity Index; S-CVR: Scale-level Content Validity Ratio; SF-36: 36-Item Short-Form Health Survey; WHO-QOLBref: qWorld Health Organization quality of life

\section{Acknowledgements}

We are grateful to the participants in the study, as well as the health providers, for generously providing us with their experience.

\section{Authors' contributions}

SM: Project development, Data Collection, Manuscript writing, MS: project administration, writing-review and editing, supervision. FR: project administration, writing-review and editing, supervision. NK: project administration, writing-review and editing, supervision. HA: project administration, data analysis. All authors have read and approved the final manuscript.

\section{Funding}

This study is the result of a Phd thesis and was supported by the shahid beheshti University, Tehran, Iran. No external funding sources were provided for this study.

\section{Availability of data and materials}

The datasets used and/or analysed during the current study are available from the corresponding author on reasonable request.

\section{Ethics approval and consent to participate}

Ethics approval (no. 1395.494) was obtained from the Ethics Committee, Faculty of Pharmacy and Nursing Midwifery, Shahid Beheshti University (date: 2015/4). Informed written consent was obtained from all participants.

\section{Consent for publication}

Not applicable.

\section{Competing interests}

The authors declare that they have no competing interests.

\section{Author details}

'Department of medical science,Qom branch, Islamic azad University, Qom, Iran. ${ }^{2}$ Professor, Midwifery and Reproductive Health Research Center, Shahid Beheshti University of Medical Sciences, Tehran, Iran. ${ }^{3}$ Professor, Gynecology Department, Reproductive Endocrinology Research Center, Research Institute for Endocrine Sciences, Shahid Beheshti University of Medical Sciences, Tehran, Iran. ${ }^{4}$ Midwifery and Reproductive Health Department, school of Nursing and Midwifery, Shahid Beheshti University of Medical Sciences, Tehran, Iran. ${ }^{5}$ Professor, Department of Biostatistics,Faculty of Paramedical Sciences, Shahid Beheshti Medical University, Tehran, Iran.

\section{Received: 23 August 2019 Accepted: 19 November 2019}

\section{Published online: 29 November 2019}

\section{References}

1. Cunningham F, Leveno K. Hauth J. Williams: Rouse D; 2010. p. 1361-5.

2. Sayehmiri F, Bakhtiary S, Darvishi P. Prevalence gestational diabete mellitus in Iran a systematic review and meta analysis study. IJOGI. 2013:15:16-23.

3. Halperin I, Feige D. The role of lifestyle interventions in the prevention of gestational diabete. Curr Diab Rep. 2014;14(1):452.

4. Daniells S, Grenyer BF, Davis W. Gestational diabetes mellitus: is a diagnosis associated with an increase in maternal anxiety and stress in the short and intermediate term? Diab Care. 2003:26:385-9.

5. Rumbold A, Crowther C. Women's experiences of being screened for gestational diabetes mellitus. Aust N Z J Obstet Gynaecol. 2002;42:131-7.

6. Sjogren B, Robeus N, Hansson U. Gestational diabetes: a case-control study of women's experience of pregnancy, health and the child. J Psychosoma Res. 1994;38:815-22.
7. Xu T, Dainelli L, Yu K, Ma L, Zolezzi IS, Detzel P, et al. The short-term health and economic burden of gestational diabetes mellitus in China: a modelling study. BMJ Open. 2017;7(12).

8. Zahedi M, Deris F. The quality of life in pregnant women in Farokhshahr city,2012. J Clin Nurs Midwifery. 2015;3:63-9.

9. Md W, HD-vd W. Pouwer F, Gemke R, Snoek F. Monitoring health related quality of life in adolescents with diabetes: a review of measures. Arch Dis Child. 2007;92:434-9.

10. Kopec J, Ogonowski J, Rahman M, Miazgowski T. Patient-reported outcomes in women with gestational diabetes: a longitudinal study. Int J Behav Med. 2015;22:206-13.

11. Trutnovsky G, Panzitt T, Magnet E, Stern C, Lang U, Dorfer M. Gestational diabetes: women's concerns, mood state, quality of life and treatment satisfaction. J Matern Fetal Neonatal Med. 2012;25:2464-6.

12. Dalfrà M, Nicolucci A, Bisson T, Bonsembiante B. ALapolla. QLISG (quality of life Italian study group). Quality of life in pregnancy and post-partum: a study in diabetic patients. Qual Life Res. 2012;21:291-8.

13. Mogos M, August E, Salinas-Miranda A, Sultan D, Salihu H. A systematic review of quality of life measures in pregnant and postpartum mothers. Appl Res Qual Life. 2013;8(2):219-50.

14. Kazemi F. Quality of life in pregnant women: designing and psychometric assessment [Phd]: Shahid Beheshti University of Medical Sciences; 2017.

15. Vachkova $E_{1}$ Jezeck $S$, Mares J, Moravcova M. The evaluation of the psychometric properties of a specific quality of life questionnair for physiological pregnancy. Health Qual Life Outcomes. 2013;11:214

16. Bradley C, Todd C, Gorton T, Symonds E, Martin A, Plowright R. The development of an individualized questionnaire measure of perceived impact of diabetes on quality of life: the ADDQoL. Qual Life Res. 1999:8:79-91.

17. Lee E, Lee $Y$, Lee K, Kim D, Kim S. Development and psychometric evaluation of a diabetes-specific quality-of-life (D-QOL) scale. Diabetes Res Clin Pract. 2012;95(1):76-84

18. Darvishpoor A, saeedi JA, Yaghmaie F, majd HA. Instrument Development to Measure Diabetic Clients Quality Of Life (DCQOL). IJEM. 2005;7(2):149-55.

19. Robling M, Matthews SJ, Hood K. The development of a new site-specific measure of quality of life for breast problems: the Cardiff breast scales. Qual Life Res. 2002:11(4):339-48.

20. Waltz C, Strickland O, Lenz E. Measurement in nursing and health research fourth, editor. America: Springer; 2010

21. Association A. Standards of medical care in diabetes-2011. Diabetes Care. 2011;34:11-61

22. Graneheim U, Lundman B. quantitative content analysis in nursing research: concepts, procedures and measures to achieve trust worthiness nurse educ today. Nurse Educ Today. 2004;24(2):105-12.

23. Lincoln Y, Guba E. naturalist inquiry. Hiss B, editor. California: Sage publication; 2001

24. Ware J, Sherbourne C. The MOS 36-item health survey (SF-36). I. Conceptual framework and item selection. Med Care. 1992:30:473-83.

25. WHOQOL-BREF,introduction, Administration and scoring,Field, Trial version [Internet]. World Health Organ. 1996.

26. Burroughs TE, Desikan R, Waterman BM, Gilin D. McGill JJDS. Dev Validation Diab Qual Life Brief Clin Inventory. 2004;17(1):41-9.

27. Stetson B, Schlundt D, Rothschild C, Floyd J, Rogers W, Mokshagundam S. Development and validation of the personal diabetes questionnaire (PDQ): a measure of diabetes self-care behaviors, perceptions and barriers. Diabetes Res Clin Pract. 2011:91(3):321-32.

28. Bijl J, Poelgeest-Eeltink A, Shortridge-Baggett L. The psychometric properties of the diabetes management self-efficacy scale for patients with type 2 diabetes mellitus. J Adv Nurs. 1999;30(2):352-9.

29. Garcia A, Villagomez E, Brown S, Kouzekanani K, Hanis C. The Starr County diabetes education study: development of the Spanish-language diabetes knowledge questionnaire. Diabetes Care. 2001;24:16-21.

30. Kristensen L, Thastum M, Mose A, Birkebaek N. Psychometric evaluation of the adherence in diabetes questionnaire. Diabetes Care. 2012;35(11):2161-6.

31. Rotella F, Dicembrini I, Lazzeretti L, Bigiarini M, Ricca V, Rotella C. Is there a practical way of predicting therapeutic success in type 2 diabetes on the basis of psychological features? Development and validation of the psychological predictors of therapeutic success in diabetes (PPTD) questionnaire. Acta Diabetol. 2014;51(1):133-40.

32. Khoshrang H, Dadgaran I, Shaigan H. Designing a questionnaire to measure threats and opportunities of E-learning and determining its psychometric properties. Cheshmeh: Tehran; 2014. 
33. Lawshe C. A quantitative approach to content validity. Pers Psychol. 1975; 28(4):563-75.

34. Polit D, Beck C. Essentials of nursing research: appraising evidence for nursing practice Wolters kluwer health/lippincott Williams and wilkins; 2010

35. Munro B. Statistical methods for health care research. NEW YORK: Lippincott Williams and Wilkins; 2005

36. Tavakol M, Dennick R. Making sense of Cronbach's alpha. Int J Med Educ. 2011:2:53-5.

37. Yarmohamadiasl $M$, Narenjiha $H$, Rafiai $H$. Construct and validate the life skills exam in substance dependent patients. J of Soc Welf. 2009:151-76.

38. Draffin C, Alderdice F, McCance D, Maresh M, Holmes V. Exploring the needs, concerns and knowledge of women diagnosed with gestational diabetes: a qualitative study. Midwifery. 2016;40:141-7.

39. Whitty-Rogers J, Caine V, Cameron B. Aboriginal Women's experiences with gestational diabetes mellitus: a participatory study with Mi'kmaq women in Canada. ANS Adv Nurs Sci. 2016;39(2):181-98.

40. Persson M, Winkvist A, Mogren I. From stun to gradual balance'--women's experiences of living with gestational diabetes mellitus. Scand J Caring Sci. 2010;24(3):454-62.

41. Munro B. statistical methods for health care research. philadelphia: lippincott,williams and wilkins; 2005.

42. Nolan JA, McCrone S, Chertok IR. The maternal experience of having diabetes in pregnancy. J Am Acad Nurse Pract. 2011;23(11):611-8.

43. Ghui A, Harvey D, Salamon E. Stress and anxiety in women with gestational diabetes during dietary management. Diabetes Educ. 2014;40(5):668-77.

44. Hirst J, Tran T, Do M, Rowena F, Morris JW. Women with gestational diabetes in Vietnam: a qualitative study to determine attitudes and health behaviours. BMC Pregnancy Childbirth. 2012;91(12):81.

45. Fde OS, Dias L, Mde MF, Guirro E, Rde CC, Lara L. Assessment of female sexual function in pregnant women with gestational diabetes mellitus. J Sex Med. 2013;10(5):1350-4.

46. Larijani B, Nezhad A. Symptom and clinical features in pregnant women with different degree of carbohydrate intolerance. Iran J Diabetes Metab. 2004;2:129-42.

47. Richard T, Maria J, Ellen L. Diabetes in pregnancy among first nations women. Qual Health Res. 2014;11:1469-80.

48. Devsam B, Bogossian F, Peacoc A. An interpretive review of women's experiences of gestational diabetes mellitus:proposing a framework to enhance midwifery assessment. Women Birth. 2013;26(2):69-76.

49. Han S, Middleton P, Bubner T, Crowther C. Women's views on their diagnosis and Management for Borderline Gestational Diabetes Mellitus. J Diabetes Res. 2015:1-9.

50. Otchet F, Carey M, Adam L. General health and psychological symptom status in pregnancy and the Puerperium: what is Normal? Obstet Gynecol. 1999:94:935-41.

51. Polit D, Beck C. Essentials of nursing research: appraising evidence for nursing practice. philadelphia, lippincott williams and wilkins; 2016.

52. Nasiri-Amiri F, Tehrani FR, Simbar M, Montazer A. Mohaammadpour R. Health-related quality of life questionnaire for polycystic ovary syndrome (PCOSQ-50): development and psychometric properties. Qual Life Res. 2016; 25:1791-801.

\section{Publisher's Note}

Springer Nature remains neutral with regard to jurisdictional claims in published maps and institutional affiliations.

Ready to submit your research? Choose BMC and benefit from:

- fast, convenient online submission

- thorough peer review by experienced researchers in your field

- rapid publication on acceptance

- support for research data, including large and complex data types

- gold Open Access which fosters wider collaboration and increased citations

- maximum visibility for your research: over $100 \mathrm{M}$ website views per year

At $\mathrm{BMC}$, research is always in progress.

Learn more biomedcentral.com/submissions 